\title{
Assessing microbial colonization of peripheral intravascular devices
}

\author{
Li Zhang ${ }^{1 *}, \mathrm{PhD}$; \\ Nicole Marsh ${ }^{1,2}, \mathrm{BN}$ \\ Matthew R McGrail ${ }^{3}, \mathrm{PhD}$; \\ Joan Webster ${ }^{1,2}$, BA; \\ Elliott G Playford ${ }^{4}, \mathrm{PhD}$ \\ Claire M. Rickard ${ }^{1,2,4}, \mathrm{PhD}$
}

${ }^{1}$ Griffith Health Institute-Health Practice Innovation, Griffith University, Nathan, Queensland, Australia;

${ }^{2}$ Research Development Unit, Centre for Clinical Nursing, Royal Brisbane and Women's Hospital, Herston, Queensland, Australia;

${ }^{3}$ School of Rural Health, Monash University, Gippsland, Victoria; Australia;

${ }^{4}$ Infection Management Services, Princess Alexandra Hospital, Woolloongabba, Queensland Australia.

*Correspondence: Li Zhang, N48 Nathan Campus, Griffith University, 170 Kessels Road, Nathan QLD 4111, Australia. Tel: +61 7 37357272; Fax: +61 7 3735 3560; Email:li.zhang@griffith.edu.au. 


\section{Dear Editor,}

We read with interest the recent paper by Molina $\mathrm{J}$ et al., which discussed mortality and hospital stay related to coagulase-negative staphylococci bacteraemia caused by intravascular devices (IVD) in non-critical patients. ${ }^{1}$ The most frequently isolated bacteria on IVD are coagulase-negative staphylococcus, ${ }^{2}$ it is, therefore, critical for researcher to assess IVD related infections and develop efficient strategies to prevent IVD-related infections.

Peripheral intravascular devices (PIVDs) are one of the most frequently used medical invasive devices in hospitals ${ }^{3}$ and it is estimated that 200 million PIVDs are used annually in the USA. ${ }^{4}$ PIVD-related infections occur at lower incidence than many other IVD types, but constitute serious and potentially life-threatening infections, exacerbated by the high frequency of use. ${ }^{5}$ To reduce the incidence of PIVD-related infections, many strategies have been applied including hand hygiene, aseptic technique during PIVD insertion and skin preparation. ${ }^{6}$ In many hospitals, peripheral catheters are inserted by medical staffs with limited experience in IV catheter care. Several studies have suggested that a dedicated IV therapy team may reduce catheter-related complications. ${ }^{7}$ In addition, routine replacement of catheters was believed to be the critical factor in reducing the occurrence of complications. Furthermore, an intervention to reduce PIVD-related infection used in recent years has been to artifically shorten the dwell time of individual devices. ${ }^{2}$ We conducted a randomized, prosepctive, controlled trial to assess how time in situ contributes to PIVD colonization; to assess the effectiveness of routine Day 3 removal of PIVDs in preventing microbial colonization; and to assess whether the use of IV team decreases PIVD complication.

After ethics committee approval, and patients' informed consent, the study was conducted at three teaching hospitals in Queensland, Australia. PIVDs were inserted and cared for in accordance with usual hospital practice except for the approach to catheter removal which was randomized to either removal on clinical indication (clinical change 
group: $\mathrm{CC}$ ), or routinely every three days (routine change group: RC). Randomization was a 1:1 ratio, computer generated after patient consent, and concealed until this time. Clinical staffs were then aware of allocation but the endpoint raters for colonization were blinded. IV teams inserted $40 \%$ of devices, with the remainder-inserted by general medical and nursing staff. PIVDs were Insyte Autoguard (BD Medical, Franklin Lakes, USA). Dressings (transparent semi-permeable) were used for 7 days, or changed earlier if loose or soiled. A 5\% convenience sample was taken. When the PIVD was no longer required, the nurse removed the PIVD and distal $2 \mathrm{~cm}$ of the tip was cut. All PIVD tips were handled under aseptic conditions and immediately transported to laboratory and cultured by the semiquantitative method. ${ }^{8}$ Baseline characteristics of patients and devices, all of which are described as frequencies (\%) except for age (mean and SD), were compared using a twosided Fisher's exact test. Relative incidence rates (RR) of PIVD-related colonization per 100 devices/patients and also aggregated incidence rate ratio comparisons (IRRs) per 1,000 device days, both with $95 \%$ confidence intervals, were calculated to compare colonization rates. Median dwell times were compared using the Mann-Whitney test. Multivariate (Cox regression) modelling assessed possible associations between age, gender, number of comorbidities, study group, hospital, inserter type, insertion site, IV antibiotics or other IV medications with colonization rates. Statistical analysis was completed using StataSE (Version 10, College Station, TX). P values of $<0.05$ were considered statistically significant.

A total of 298 PIVDs were studied in 260 patients. The median patient age was 56 years and $64 \%$ were male. One hundred and forty six (55\%) patients had multiple comorbidities. Of the 260 patients, 127 were randomised to receive routine PIVD change (RC group) and 133 patients were randomised to the clinical change group (CC group). Eight of $143(6.3 \%)$ (CC) vs 6 of $155(4.5 \%)$ (RC) PIVDs were colonized, and this was not statistically different between groups (see Table 1). The most frequently identified organism 
was coagulase-negative staphylococcus. Others included staphylococcus, bacillus, candida, corynebacterium and streptococcus species. Median PIVD time in situ was significantly longer in colonized than uncolonized PIVDs, but this was not significant when viewed by study group as rates per 1000 PIVD days (CC 14.6/1000 PIVD Days vs RC 14.4/1000 PIVD Days, IRR 1.02, 95\% CI 0.34-3.21, p=0.98, Table 1). Multivariate (time-adjusted per 1000 PIVD days) modelling found no significant variables (including study group) associated with colonization. The application of IV team might decrease PIVD-related infections but the difference was not statistically significant $(p=0.06)$. No statistically significant differences were seen regarding the other evaluation criteria on PIVD colonization: gender, age, insertion site, hospital, antibiotic treatment and intravascular medications.

The results suggest that increased dwell time is significantly associated with colonization, and this is not prevented by routinely removing devices. Over the course of a treatment period, the rates of colonization are not significantly different when PIVDs are left in situ as long as clinically needed and they remain functional, compared to removal every 34 days. The observed colonization rate was $4.7 \%$ at a threshold of $15 \mathrm{cfu}$. Few studies have been published that deal specifically with PIVD colonization. One French study of prehospital inserted PIVDs found a similar rate of $4.1 \%$ colonization, despite patient and analytic differences. ${ }^{9}$ Our devices would not usually have been cultured in clinical practice and clinicians would assume that they were sterile, when our findings show that this is not the case. Insertion by an IV team appeared somewhat protective of colonization although was not remain predictive on the multivariate analysis. The most frequently isolated microbes in this study were coagulase-negative staphylococci, and this is consistent with the findings of colonization in many IVD types. ${ }^{2}$ However, it has been shown that culture methods although commonly used, are of limited value for slow-growing or fastidious bacteria or intracellular pathogens. ${ }^{10}$ The sensitivity of the semi-quantitative method might also be reduced if the 
patient is receiving antibiotic treatment. ${ }^{10}$ Therefore, many pathogenic bacteria might not have been isolated in this study because of the techniques used, and the true bacterial colonization rate may be higher than shown here. 


\section{Funding}

C.M.R. received grant support from Australian National Health and Medical Research

Council. L.Z. is supported by Australian National Health and Medical Research Council training-clinical research fellowship (grant number 597491).

\section{Potential conflicts of interest}

All authors report no conflict of interest relevant to this article. 


\section{References}

1. Molina J, Penuela I, Lepe JA, Gutierrez-Pizarraya A, Gomez MJ, Garcia-Cabrera E, et al. Mortality and hospital stay related to coagulase-negative Staphylococci bacteremia in non-critical patients. J of Infect 2013;66(2):155-162.

2. Mermel LA, Allon M, Bouza E, Craven DE, Flynn P, O'Grady NP, et al. Clinical Practice Guidelines for the Diagnosis and Management of Intravascular CatheterRelated Infection: 2009 Update by the Infectious Diseases Society of America. Clin Infect Dis 2009;49(1):1-45.

3. Zingg W, Pittet D. Peripheral venous catheters: an under-evaluated problem. International Journal of Antimicrobial Agents. 2009;34 Suppl 4:S38-42.

4. Maki DG. Improving the safety of peripheral intravenous catheters. BMJ 2008;337(7662).

5. Maki DG, Kluger DM, Crnich CJ. The risk of bloodstream infection in adults with different intravascular devices: a systematic review of 200 published prospective studies. Mayo Clinic Proc 2006;81(9):1159-1171.

6. O'Grady NP, Alexander M, Burns LA, Dellinger EP, Garland J, Heard SO, et al. Guidelines for the Prevention of Intravascular Catheter-related Infections. Clin Infect Dis 2011;52(9):e162-e193.

7. Soifer NE, Borzak S, Edlin BR, Weinstein RA. Prevention of peripheral venous catheter complications with an intravenous therapy team - A randomized controlled trial. Arch Intern Med 1998;158(5):473-477.

8. Maki DG, Weise CE, Sarafin HW. A semiquantitative culture method for identifying intravenous catheter-related infections. N Engl J Med 1977;296:1305-1309.

9. Ezingeard E, Coudrot M, Guyomarc'h S, Aubert G, Blanc JL, Bertrand JC, et al. Evaluation of colonisation of peripheral venous catheters inserted by prehospital emergency service teams (SMUR) in France. J Hosp Infect 2009;72(2):169-175.

10. Mancini N, Carletti S, Ghidoli N, Cichero P, Burioni R, Clementi M. The Era of Molecular and Other Non-Culture-Based Methods in Diagnosis of Sepsis. Clin Microbiol Rev 2010;23(1):235-+. 
Table 1. Peripheral intravascular device (PIVD) colonization according to patient and intervention characteristics.

\begin{tabular}{|c|c|c|c|c|}
\hline Variable & $\begin{array}{l}14 \text { colonized } \\
\text { PIVD }\end{array}$ & $\begin{array}{l}284 \text { uncolonized } \\
\text { PIVD }\end{array}$ & $\begin{array}{c}\text { Risk ratio or } \\
\text { mean difference } \\
95 \% \mathrm{CI}\end{array}$ & $P$ \\
\hline \multicolumn{5}{|l|}{ Study group } \\
\hline Clinical change group & 8 & 135 & \multirow{2}{*}{$1.44(0.51-4.06)$} & \multirow{2}{*}{0.59} \\
\hline Routine change group & 6 & 149 & & \\
\hline $\begin{array}{l}\text { Time in situ, median } \\
\text { (quartiles) }\end{array}$ & $118.5(73,173)$ & $72.5(55,98)$ & $44.5(13.9-75.2)$ & 0.004 \\
\hline \multicolumn{5}{|l|}{ Gender } \\
\hline Male & 10 & 191 & \multirow{2}{*}{$1.33(0.43-4.14)$} & \multirow{2}{*}{0.78} \\
\hline Female & 4 & 103 & & \\
\hline Age (years) $($ mean $\pm S D)$ & $51.0 \pm 19.4$ & $55.8 \pm 18.3$ & $4.8(7.9-17.5)$ & 0.46 \\
\hline \multicolumn{5}{|l|}{ Inserter type } \\
\hline IV service & 3 & 139 & \multirow{2}{*}{$0.30(0.09-1.05)$} & \multirow{2}{*}{0.06} \\
\hline Other clinician & 11 & 145 & & \\
\hline \multicolumn{5}{|l|}{ Insertion site } \\
\hline Ward & 10 & 222 & \multirow{3}{*}{ N/A } & \multirow{3}{*}{0.13} \\
\hline Emergency & 0 & 27 & & \\
\hline $\begin{array}{l}\text { Operating theatre / } \\
\text { Radiology }\end{array}$ & 4 & 35 & & \\
\hline \multicolumn{5}{|l|}{ Hospital } \\
\hline 1 & 3 & 96 & \multirow{3}{*}{ N/A } & \multirow{3}{*}{0.52} \\
\hline 2 & 7 & 100 & & \\
\hline 3 & 4 & 88 & & \\
\hline \multicolumn{5}{|l|}{ IV antibiotics } \\
\hline Yes & 12 & 209 & \multirow{2}{*}{$2.09(0.48-9.13)$} & \multirow{2}{*}{0.53} \\
\hline No & 2 & 75 & & \\
\hline \multicolumn{5}{|l|}{ IV medications } \\
\hline Yes & 5 & 126 & \multirow{2}{*}{$0.71(0.24-2.06)$} & \multirow{2}{*}{0.59} \\
\hline No & 9 & 158 & & \\
\hline
\end{tabular}

IV - intravenous. 